\title{
Microstructure of Cured Urea-Formaldehyde Resins Modified by Rubber Latex Emulsion after Hydrolytic Degradation ${ }^{1}$
}

\author{
Arif Nuryawan ${ }^{2} \cdot$ Byung-Dae Park ${ }^{2, \dagger}$
}

\begin{abstract}
This study investigated microstructural changes of cured urea-formaldehyde (UF) resins mixed with aqueous rubber latex emulsion after intentional acid etching. Transmission electron microscopy (TEM) was used in order to better understand a hydrolytic degradation process of cured UF resins responsible for the formaldehyde emission from wood-based composite panels. A liquid UF resin with a formaldehyde to urea $(\mathrm{F} / \mathrm{U})$ molar ratio 1.0 was mixed with a rubber latex emulsion at three different mixing mass ratios (UF resin to latex $=30: 70,50: 50$, and 70:30). The rate of curing of the liquid modified UF resins decreased with an increase of the rubber latex proportion as determined by differential scanning calorimetry (DSC) measurement. Ultrathin sections of modified and cured UF resin films were exposed to hydrochloric acid etching in order to mimic a certain hydrolytic degradation. TEM observation showed spherical particles and various cavities in the cured UF resins after the acid etching, indicating that the acid etching had hydrolytically degraded some part of the cured UF resin by acid hydrolysis, also showing spherical particles of cured UF resin dispersed in the latex matrix. These results suggested that spherical structures of cured UF resin might play an important role in hindering the hydrolysis degradation of cured UF resin.
\end{abstract}

Keywords : acid hydrolysis, cured urea-formaldehyde resin, microstructure, rubber latex, spherical particles, transmission electron microscopy

\section{INTRODUCTION}

For many decades, urea-formaldehyde (UF) resins have been the predominant thermosetting adhesive used worldwide for appearance grade wood basedcomposite panels. Owing to many advantages such as fast curing, good strength in the panels, colorless, and low cost, UF resins are extensively used for manufacturing particleboard or fiberboard in industrial practice. However, there are two main drawbacks of
UF resins: firstly, formaldehyde emission from UF resin-bonded wood composite panels, and secondly, hydrolysis when they were exposed to water or moisture. Hydrolysis of cured UF resins was mainly responsible for the formaldehyde emission in long term and low water resistance (Myers and Koutsky 1990; Chuang and Maciel 1994; Tohmura et al. 2000). The hydrolysis of UF resins is due to reversible reactions to their synthesis reactions; exposing UF resin-bonded wood composite panels to water

1 Date Received May 26, 2014, Date Accepted July 25, 2014

2 Department of Wood and Paper Sciences, Kyungpook National University, Daegu 702-701, Rep. of Korea

† Corresponding author : Byung-Dae Park (e-mail: byungdae@knu.ac.kr) 
causes a loss of board integrity and formaldehyde emission.

Some studies investigated the hydrolysis of UF resins to understand the mechanism of bond strength loss and formaldehyde released using neat cured UF resin (Dutkiewicz 1983; 1984; Tohmura et al. 2000; Ringena et al. 2006; Abdullah and Park 2009; Park and Jeong 2011a; 2011b), and UF resin-bonded wood panel products (Irleand Bolton 1988; Ebewele et al.1991; Park et al. 2006; Roffael and Hüster 2012). Furthermore, some authors have attempted to examine the morphology of cured UF resins. Park and Jeong (2011a; 2011c) investigated effects of acid hydrolysis on the microstructure and micromorphology of cured UF resins using atomic force microscopy (AFM) and scanning electron microscopy (SEM), respectively. Their results showed two distinctive phases, hard and soft phases in AFM images. They also reported the presence of filament-like sharp crystalline structures on the fracture surface which was more resistant to the hydrolytic degradation than that of the soft phase after the acid etching. In addition, spherical structures within the fracture surface of cured UF resin were much more dominant after the acid etching. They concluded that the amorphous region was degraded by the hydrolysis, while the crystalline spherical structures rather resisted and were prevailingly on the facture surface after the acid etching.

In general, thermosetting polymers contain a certain inhomogeneity in their cured state. Indeed, the existence of the heterogeneity of thermosetting resin as nodular structures with particle sizes ranging from tens to hundreds nanometers on free and etched fracture surfaces of cured resin has been reported (Spurr et al. 1957; Racich and Koutsky 1976; Gupta et al. 1985; Dušek 1996). In the case of cured UF resins, several authors concluded that the presence of nodular structures or spherical particles was a result of colloid formation (Pratt et al. 1985; Stuligross and Koutsky 1985; Depres and Pizzi 2006; Ferra et al. 2010). Moreover, John and Dunker (1986) and Motter (1990) stated that the UF colloidal dispersion has been shown to be partly crystalline. Further, evidence was provided that crystallinity was inherent within cured UF resins using SEM (Park and Jeong 2011a), small-angle X-ray scattering (SAXS) and wide-angle X-ray scattering (WAXD) (Park and Causin 2013). Recently, Singh et al. (2013) reported evidence of heterogeneity of cured UF resin covering up to nanoscale; coarsely granular region of UF resins that contain both globular/nodular particles and crystalline structures, as crystal aggregations and small developing crystals. Globular/nodular particles appeared to be the site of emerging or immature crystals, while the distinct crystal such as needle-like structure and fan-shape structure were mature crystals (Singh et al. 2014).

The aforementioned reports suggested that globular/spherical particles which have been described as nodular, globular, colloidal, and spherical structures were crystalline, and resistant to hydrolytic degradation. However, there is still an information gap in understanding the hydrolysis process of cured UF resin. Therefore, in this contribution, UF resins were modified by mixing with aqueous rubber latex emulsion in order to study the hydrolytic degradation process of cured UF resin. Thus, we intentionally attempted to keep cured UF resin trapped in the latex matrix to identify morphological changes of cured UF resins by hydrolytic degradation before and after the acid etching. We selected a commercial styrene butadiene rubber latex emulsion because it is resistant to the acid etching as a hydrolysis process. Microstructure of modified and cued UF resins were investigated by TEM for the samples with different mixing ratios of UF resin to the latex emulsion after the acid etching as a simulation of the hydrolysis process. 


\section{MATERIALS and METHODS}

\subsection{Materials}

Technical grade urea granules (99\%) and formalin (37\%) were used for the synthesis of UF resins. Aqueous solutions of both formic acid (20 wt\%) and sodium hydroxide (20 wt\%) were used to adjust the $\mathrm{pH}$ level during liquid UF resin synthesis. Commercial styrene-butadiene latex emulsion (KUMHO KSL 106, Korea Kumho Petrochemical Co., Ltd., Korea) with the solid content of 48\%, pH 8.0, viscosity 190 mPa.s, and particle size $170 \mathrm{~nm}$ was used as modifier. An aqueous solution (20\%) of ammonium chloride $\left(\mathrm{NH}_{4} \mathrm{Cl}\right)$ was used as hardener.

\subsection{Experimental Methods}

\subsubsection{Synthesis of Liquid UF Resins and Their Properties}

The liquid UF resin with molar ratio $\mathrm{F} / \mathrm{U}=1.0$ was prepared in the laboratory following a conventional alkaline-acid two-step reaction by adding the second urea. Sodium hydroxide and formic acid were used to adjust $\mathrm{pH}$ at $7.8 \sim 8.0$ for methylolation (addition reaction) and to control $\mathrm{pH}$ at 4.6 for the condensation reaction. Briefly, formalin (37\%) was placed in the glass cooking reactor with the mantle heater. Then, the $1^{\text {st }}$ urea was placed into the reactor, yielding a molar ratio $\mathrm{F} / \mathrm{U}=2.0$. The mixture was heated to $90^{\circ} \mathrm{C}$ for $60 \mathrm{~min}$ to allow the methylolation reaction. The temperature was then adjusted to $80^{\circ} \mathrm{C}$; the condensation reaction was carried out in the acidic range up to target viscosity of $\mathrm{JK}$, which was measured using a bubble viscometer (VG-9100, Gardner-Holdt Bubble Viscometer, USA). When the condition was reached, the second urea was added to the reactor using funnel. After all of the urea dissolved, the UF resin was cooled to room temperature, and the $\mathrm{pH}$ was subsequently adjusted to 8.0.

The resin solids was determined to $57.7 \%$ by measuring $1 \mathrm{~g}$ of UF resin in a disposable aluminum dish before and after drying in a convective oven at $105^{\circ} \mathrm{C}$ for 3 hours. Viscosity was $245 \mathrm{mPa}$.s measured at $25{ }^{\circ} \mathrm{C}$ with No. 2 spindle at 60 rpm by a rotational viscometer (DV-II+, Brookfield, USA). Gel time was 162 seconds when it was measured at 10 $0^{\circ} \mathrm{C}$ by adding $3 \% \mathrm{NH}_{4} \mathrm{Cl}$ (20 wt\%) measured at boiling water by a gel time meter (Davis Inotek Instrument, Charlotte, NC). All the measurements were carried out by three replications and the average value was taken a result.

\subsubsection{Preparation and Thermal Curing Behavior of Liquid Modified UF Resins}

The liquid modified UF resins were prepared by simple mixing UF resin with the latex emulsion at different proportions based on resin solid content, using three different mixing ratios of UF resin to the latex: 30:70, 50:50, and 70:30. The mixtures were thoroughly stirred by hands, and then used to prepare the resin films.

Prior to preparing cured UF resin films, first, thermal curing behavior of the liquid modified UF resins was investigated using differential scanning calorimetry (DSC) in order to confirm that modified UF resin has been cured. The modified UF resins were physically mixed with $3 \% \mathrm{NH}_{4} \mathrm{Cl}$ (20 wt\%) based on the non-volatile solids content of UF resin. About 5 mg of the mixtures were sealed into a hermetic pan and covered with a lid and subsequently scanned by a pressurized DSC (Q10, with software Universal Analysis 2000, V4.5A, TA Instruments, New Castle, DE, USA) at $10^{\circ} \mathrm{C} \mathrm{min}^{-1}$ heating rate. All samples were scanned in a temperature range from 40 to 30 $0^{\circ} \mathrm{C}$ under $0.689 \mathrm{mPa}$ pressure with nitrogen gas and peak temperature of the exothermic curve was evaluated. 


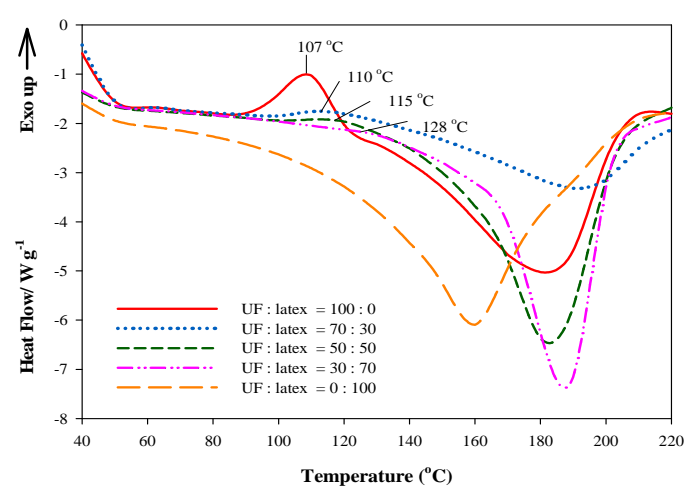

Fig. 1. DSC curves of pure UF resin, pure latex, and modified UF resins at different mixing ratios of UF resin to the latex with $3 \%$ hardener.

\subsubsection{Preparation of Modified and Cured UF Resin Films}

About $3 \mathrm{~g}$ of each mixture was placed in an aluminum weighing boat ( $5 \mathrm{~cm}$ diameter), cured at $50^{\circ} \mathrm{C}$ for $24 \mathrm{~h}$ in a vacuum oven to prepare resin films of approximately $1 \mathrm{~mm}$ thickness with three replications. These films were then stored in desiccators before use.

\subsubsection{Sample Preparation for TEM Imaging}

The modified and cured UF resin films were cut into a small stripes (cross section about $1 \mathrm{~mm} \times 1$ $\mathrm{mm}$ and length $10 \mathrm{~mm}$ ), and then infiltrated with, and embedded in Spurr's resin, according to the method described elsewhere in detail (Singh et al. 2013). Ultrathin sections of the embedded stripes perpendicular to the length resins were obtained by an ultramicrotome with a diamond knife, and were then placed on grids and divided into two series: control and acid etching samples. To simulate the hydrolysis process, the prepared ultrathin section on the grid was etched by application of one droplet of $0.1 \mathrm{~N}$ hydrochloric acid solutions onto the surface for one minute. Both series of the samples then were stained for 7 minutes with $2 \%$ aqueous uranyl acetate solution and dried at room temperature. In con- sideration of the possible influence of the infiltration and embedding process, also ultrathin section of modified UF resin without infiltration and embedding in Spurr's resin were prepared.

The ultrathin sections were examined with TEM (H-7100, Hitachi, Japan, located at Korea Basic Science Institute, Daegu, Korea), operating at $75 \mathrm{kV}$.

Preliminary tests had shown that modified and cured UF resins films with less than $30 \%$ of the latex in the blends were destroyed due to their high brittleness when they were used for trimming or ultrathin sectioning. Therefore only the mixing ratios of UF resin to the latex of 30:70, 50:50, and 70:30, respectively, were selected for all sample preparations of TEM imaging. For all quantitative measurements, image analysis software (i-solution, Image and Microscope Technology, Vancouver, Canada) was used in order to determine the particle diameter using TEM micrographs. An average of at least 25 measurements of particles was provided.

\section{RESULTS and DISCUSSION}

\subsection{Curing Behavior of Modified UF Resins}

The results presented in Fig. 1 show typical DSC curves to understand thermal curing behavior of liquid modified UF resins. The DSC curve of the pure rubber latex showed only an endothermic peak. By contrast, original and modified UF resins show an evident single exothermic peak temperature $\left(T_{p}\right)$ in the DSC curves although the modified UF resins revealed relatively small $T_{p}$. The values of $T_{p}$ increase as the latex proportion increases: $110^{\circ} \mathrm{C}, 115^{\circ} \mathrm{C}$, and $128^{\circ} \mathrm{C}$ for the ratios as mentioned above. These results suggest that as more latex added, more time is needed for the modified UF resins to reach the fully cured state. In other words, the hardening reaction is delayed due to the dilution with latex. The next im- 


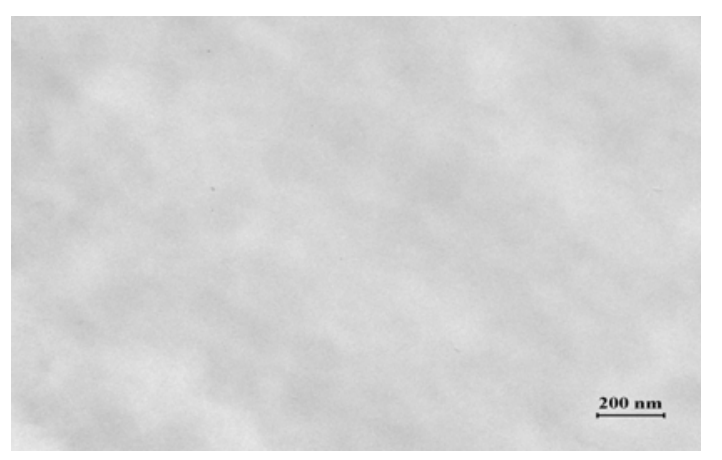

Fig. 2. A TEM micrograph of the pure rubber latex.

plication was the shifting of $T_{p}$ into higher temperature although the $T_{p}$ was small. In addition, the reaction between UF resin and latex was not changed chemically, but only physical effect of dilution. The latex is an amorphous elastomer which can influence and interfering curing properties of the blends. $T_{p}$ value for original $\mathrm{UF}$ resin was $107^{\circ} \mathrm{C}$. It was not able to obtain $T_{p}$ value for modified UF resins with greater than $80 \%$ of the latex.

\subsection{Microstructures of Modified UF Resins}

Prior to describing the microstructure of modified UF resins, it was necessary to clearly distinguish the UF resin components from the UF resin/latex blends in TEM micrographs. Fig. 2 shows the TEM micrograph obtained for an ultrathin section of the pure latex (100\% styrene-butadiene latex) sample. As presented in Fig. 2, the latex matrix was generally bright and did not appear as distinct regions. In practice, ruthenium tetraoxide is being used to stain rubber latex as a standard procedure because of its phenyl rings (Bar et al. 2000). Since the work reported here was focused on the examination of the microstructure of cured UF resins containing amide group, uranyl acetate was used as a staining reagent for the cured UF resin (Singh et al. 2013). Their microstructure and micromorphology of the modified UF

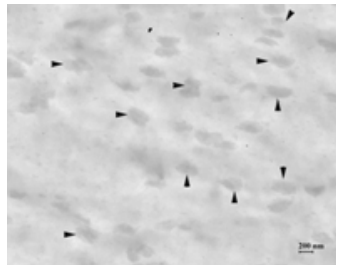

(a)



(b)
Fig. 3. TEM micrographs of modified UF resins at the mixing ratio of 30:70 for UF resin to the latex. (a) Before and (b) after the acid etching. Spherical particles (arrow heads) appear more noticeable after etching. Cavities (asterisks) appeared only after the acid etching.

resins were investigated before and after acid etching.

TEM micrographs of the modified UF resins with $30 \%$ proportion of the UF resins in the mix are shown in Fig. 3. TEM image of the control sample before the acid etching revealed dispersions of dark spherical particles of UF resin in the latex matrix, which itself was very bright (Fig. 3a). The dark color and, hence, the good contrast of the dark spherical UF particles in contrast to the bright latex indicate that the uranyl acetate has well reacted with the UF resin. The spherical particles are considered to be globular/nodular particles that had been transversely cut in the process of ultrathin section preparation. The particles have a similar morphology to the structures visualized in the previous work on UF resin (Singh et al. 2013). However, the number of the spherical particles is much more seldom than in neat cured UF resin, which fact is to be explained by the addition of $70 \%$ rubber latex. Nevertheless, TEM confirms the presence of such structures in modified UF resin, and supports the proposed colloidal characteristics of this resin (Pratt et al. 1985; Stuligross and Koutsky, 1985; John and Dunker, 1986; Motter, 1990; Ferra et al. 2010).

Fig. 3b shows a TEM micrograph after the acid etching as a simulation of acid hydrolysis. Dark par- 


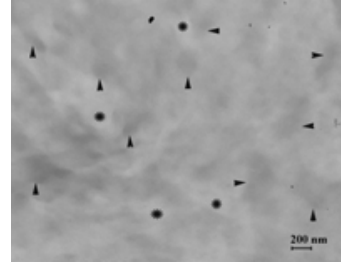

(a)



(b)
Fig. 4. TEM micrographs of modified UF resin at a ratio of UF resin to latex of 50:50: (a) Before and (b) after the acid etching. Spherical particles (arrow heads) appear quite evident after the etching. Latex (arrows) is brighter compare to dark spherical particles. Cavities (asterisks) appear extensively as the proportion of UF resin is higher than in Fig. 3.

ticles were more visible, and some evidences of hydrolytic degradation were observed. For example, either small cavities or pinholes (asterisks in Fig. 3b) present around spherical particles appeared apparent compared to those in the control micrograph. This indicates that the amorphous phase of the UF resin had been attacked, while the latex and the crystalline particles of UF resin remained in the cured network. Latex is an amorphous elastomer which is not prone to hydrolysis. The crystalline part of UF resin is also resistant to hydrolytic degradation as reported in the previous publications (Park and Jeong 2011a; 2011b; 2011c; Park and Causin 2013; Singh et al. 2014).

Fig. 4 shows TEM micrographs of modified UF resins at the mixing ratio of 50:50 before and after the acid etching. For the modified UF resin before the acid hydrolysis the spherical particles of UF resin were clearly distinctive from the latex, indicating that they were partially covered by the latex when they were blended (Fig. 4a). Furthermore, information from manufacture, the latex particles have a smaller diameter compared to those of the spherical particle of UF resin. According to our observation using SEM (Park et al. 2013), UF resins' particles consisted of larger dominant structures with



(a)

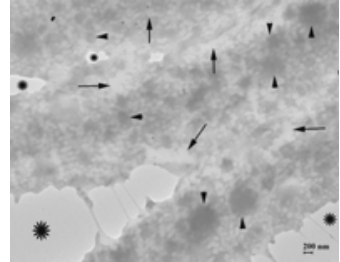

(b)
Fig. 5. TEM micrographs of modified UF resin at the mixing ratio of UF resin to the latex of 70:30: (a) Before and (b) after the acid etching. Latex particles (arrows) and spherical particle (arrow heads) appeared in both images. The exposure to the acid etching resulted in splits and cavities (asterisks) in the sample.

a diameter range between approximately 150 and $700 \mathrm{~nm}$, and substructures with a diameter range between 28 and $39 \mathrm{~nm}$. In addition, the particle size of the rubber latex in the modified UF resin was around $170 \mathrm{~nm}$ in diameter, which was in the range of the manufacture's specification. This means that during the mixing process, only physical bonding occurs and not for chemical reactions, resulting no impact on the latex performance.

Fig. 4b (after acidic etching) shows a similar morphology to the one in Fig. 3b. The spherical particles were predominant and clearly visible compared to those in the control micrograph. The presence of extensive holes (asterisks in Fig. 4b) was observed, and believed to be a consequence of the acid hydrolytic degradation. This suggests a removal of amorphous phase of cured UF resin by the acid, and the occurrence of numerous holes may also result in the loss of mass due to acid hydrolysis. The mass loss of the cured UF resin with molar ratio $\mathrm{F} / \mathrm{U}=1.0$ during acid hydrolysis reaches approximately $12 \%$ as reported also earlier (Park and Jeong 2011b).

TEM micrographs of the modified UF resin at the ratio of 70:30 for UF resin and the latex before and after the acid etching are presented in Fig 5. 



Fig. 6. TEM micrographs of the ultrathin sections directly cut of the modified UF resin at the mixing ratio of UF resin to the latex of 50:50: (a) Before and (b) after acid etching, (c) and (d) at higher magnifications after the acid etching. Spherical particles (arrow heads) appear for both cases. However, substructures (arrows) and holes (asterisks) were obviously become apparent only after acid etching. The substructures at high magnifications showed variations in their size and shape.

Regardless of the acid etching, TEM micrographs of this modified UF resin displayed interesting distinctive features for both, the UF resin and the latex. The modified UF resin before acid etching contained numerous small white particles of the latex (Fig. 5a) as well as spherical particles of UF resin, confirming that such modified UF resin blends were heterogeneous materials. In this case, the latex in the minority proportion acts as matrix while the UF resin as major component contains a greater amount of cross-linking structures in the cured network.

Fig. 5b reveals that the acid etching affects the entire surface of the ultrathin section of specimen, showing broad and wide splits as well as holes. Furthermore, differences in the surface texture are clearly observed. The acid etching preferably hydrolyzed the amorphous phase of the UF resin component, which resulted in the display of crystalline re- gion (black spherical particles) and the latex matrix (white color). These results indicate that the network of cured UF resin has been hydrolyzed by the acid etching, which consequently results in the formaldehyde emission over a long period of time.

Both images of this modified UF resin before and after the acid etching enabled us to quantitatively measure the particles diameter of the latex and UF resin. Diameters of the latex particles were $157 \pm 19$ $\mathrm{nm}$ and $152 \pm 22 \mathrm{~nm}$ before and after acid etching, respectively. However, the diameter of spherical particles of UF resins was $525 \pm 157 \mathrm{~nm}$ before the acid etching, while it decreased to $427 \pm 156 \mathrm{~nm}$ after the etching. These results confirmed that the latex particle was resistant to the hydrolysis. By contrast, the decrease in the diameter of the spherical particles of the UF resin indicates a slight hydrolysis of the crystalline particles as explained by Bikaris et al. (2006). This could be attributed to a limited diffusion of the acid into the cured UF resin polymer as well as into the crystalline phase. Acid hydrolysis occurs only on the boundary of the spherical particles; this means that acid hydrolysis can also occur partly in the crystalline phase, but only to a certain extent and only at the edges of the crystalline structures.

As the latex content increased to $50 \%$ in the blend, we were able to directly cut the ultrathin sections of the modified UF resin without dehydration procedure and embedding them in the Spurr's resin. Moreover, it is possible to ultrathin section using a glass knife. Fig. 6 displays TEM images of the modified UF resin at this mixing ratio before and after the acid etching, and exhibits a darker contrast compared to those of embedded ones. These differences were ascribed to the ultrathin sectioning method using a glass knife, instead of the diamond knife, which provides a thicker ultrathin section. If we used diamond knife, the resulted thickness of section 
was $70 \mathrm{~nm}$. However, using glass knife, the possible thickness was $90 \mathrm{~nm}$. The ultrathin sections directly cut from modified UF resin before the etching exhibited the white latex matrix and black spherical particles of UF resin (Fig. 6a). Diameter measurements of the spherical particles from the directly cut ultrathin section provided an average of $514 \pm 130$ $\mathrm{nm}$, which was quite consistent with those of the embedded sample.

After the acid etching, there are a few changes, such as a slight decrease in the diameter size of spherical particles, emergence of holes, and clearly visible substructures as increasing the black contrast. The average diameter of spherical particle was $484 \pm$ $128 \mathrm{~nm}$ which was quite similar to those from the embedded samples. The formation of holes or cavities could be due to either the removal of amorphous or sol fractions scattered in cured UF resins, or the degradation result of nano-architecture of UF resin that had been trapped in the latex matrix (Park et al. 2013). TEM images at high magnifications displayed in Fig. 6c and 6d also revealed cavities and fragments that were distributed throughout the samples. The fragments could be part of distinct crystalline particles because the shape was irregular and similar to those observed in the previous work (Park and Jeong 2011a; Singh et al. 2014). The length of fragments varied from the longest of 157 $\mathrm{nm}$ to the shortest of $9 \mathrm{~nm}$, with the average of 57 $\pm 38 \mathrm{~nm}$.

The comparison of TEM images from the directly cut samples (Fig. 6) with those from embedded samples (Figs. 2 5) suggests that the infiltration of and embedding with Spurr's resin did not influence the microstructure of the cured UF resin. The acid etching of ultrathin sections obtained by either the direct cut or the embedded blocks started to degrade the modified UF resins. The amorphous phases of UF resin was initially attacked by acid etching via hy- drolysis, which consequently resulted in cavities throughout the ultrathin section. The diameter of the spherical particles was in the range as reported of the previously using SEM (Park et al. 2013). It is believed that irregular fragments are originated from a part of crystalline structures trapped between the latex matrices. These types of structures were resistant to acid hydrolysis because they remained even after the artificial hydrolysis.

\section{CONCLUSION}

The modification of a UF resin by mixing with rubber latex to keep the UF resin trapped in the latex matrix was successfully used for investigating the microstructure and micromorphology of modified and cured UF resins before and after acid etching, using TEM. The amorphous phase of the modified and cured UF resins was susceptible to acid hydrolysis whereas spherical crystalline particles were resistant to acid etching. A slightly decrease in the diameter of spherical particles after the acid etching indicated that the acid also can hydrolyze the edges of crystalline structures. The irregular shapes of fragments observed in TEM images are believed to be resulted from distinctive or crystalline particles of modified UF resin. This study, hence, added further information using TEM concerning hydrolytic degradation processes of cured UF resins by acid hydrolysis.

\section{REFERENCES}

Abdullah, Z.A., Park, B.D. 2009. Hydrolytic stability of cured urea-formaldehyde resins modified by additives. Journal of Applied Polymer Science 114: 1011 1017 .

Bar, G., Ganter, M., Brandsch, R., Delineau, L., Whangbo, M.H. 2000. Examination of butadiene/styrene-co-butadiene rubber blends by tap- 
ping mode atomic force microscopy. Importance of the indentation depth and reduced tip-sample energy dissipation in tapping mode atomic force microscopy study of elastomers. Langmuir 16(13): 5702 5711.

Bikaris, D.N., Papageorgiou, G.Z., Achilias, D.S. 2006. Synthesis and comparative biodegradability studies of three poly(alkylene succinate)s. Polymer Degradation and Stability 91: 31 43.

Chuang, I.S., Maciel, G.E. 1994. NMR study of the stabilities of urea-formaldehyde resin components toward hydrolytic treatments. Journal of Applied Polymer Science 52: 1637 1651.

Depres, A., Pizzi, A. 2006. Colloidal aggregation of aminoplastic polycondensation resins: urea-formaldehyde versus melamine-formaldehyde and melamine-urea-formaldehyde resins. Journal of Applied Polymer Science 100: 1406 1412.

Dušek, K. 1996. Are cured thermoset resins inhomogeneous? Die Angewandte Makromolekulare Chemie 240: 1 15.

Dutkiewicz, J. 1983. Hydrolytic degradation of cured urea-formaldehyde resin. Journal of Applied Polymer Science 28: 3313 3320 .

Dutkiewicz, J. 1984. Preparation of cured urea-formaldehyde resins of low formaldehyde emission. Journal of Applied Polymer Science 29: 45 55.

Ebewele, R.O., Myers, G.E., River, B.H., Koutsky, J.A. 1991. Polyamine-modified urea-formaldehyde resins. I. Synthesis, structure, and properties. Journal of Applied Polymer Science 47: 2997 3012.

Ferra, J.M.M., Mendes, A.M., Costa, M.R.N., Carvalho, L.H., Magalhães, F.D. 2010. A study on the colloidal nature of urea-formaldehyde resins and its relation with adhesive performance. Journal of Applied Polymer Science 118: 1956 $\sim 1968$.

Gupta, V.B., Drzal, L.T., Adams, W.W. 1985. An electron microscopic study of the morphology of cured epoxy resin. Journal of Material Science 20: $3439 \sim 3452$.

Irle, M.A., Bolton, A.J. 1988. Physical aspects of wood adhesive bond formation with formaldehyde based adhesives. Part II. Binder physical properties and particleboard durability. Holzforchung 42: $53 \sim 58$.

John, W.E., Dunker, A.K. 1986. Urea-formaldehyde resin. In: Meyer B, Andrew BAK, Reinhardt RM, eds. Formaldehyde release from wood products. The American Chemical Society, pp. 76 86.

Motter, W.K. 1990. The formation of the colloidal phase in low mole ratio urea-formaldehyde resins. PhD Dissertation. Department of Mechanical and Materials Engineering. Washington State University, Pullman, USA.

Myers, G.E., Koutsky, J.A. 1990. Formaldehyde liberation and cure behavior of urea-formaldehyde resins. Holzforschung 44: 117 126.

Park, B.D., Kang, E.C., Park, J.Y. 2006. Effects of formaldehyde to urea mole ratio on thermal curing behavior of urea-formaldehyde resin and properties of particleboard. Journal of Applied Polymer Science 101: 1787 1792.

Park, B.D., Jeong, H.W. 2011a. Influence on hydrolytic degradation on the morphology of cured urea-formaldehyde resins of different formaldehyde/ urea mole ratios. Journal of the Korean Wood Science and Technology 39(2): 179 186 .

Park, B.D., Jeong, H.W. 2011b. Hydrolytic stability and crystallinity of cured urea-formaldehyde resin adhesives with different formaldehyde/urea mole ratios. International Journal of Adhesion and Adhesives 31: 524 529 .

Park, B.D., Jeong, H.W. 2011c. Effects of acid hydrolysis on microstructure of cured urea-formaldehyde resins using atomic force microscopy. Journal of Applied Polymer Science 122: 3255 $\sim 3262$. 
Park, B.D., Causin, V. 2013. Crystallinity and domain size of cured urea-formaldehyde resin adhesives with different formaldehyde/urea mole ratios. European Polymer Journal 49: 532 537.

Park, B.D., Singh, A.P., Nuryawan, A., Hwang, K. 2013. MRT Letter: High resolution SEM imaging of nano-architecture of cured urea-formaldehyde resin using plasma coating of osmium. Microscopy Research and Technique 76: 1108 1111.

Pratt, T.J., Johns, W.E., Rammon, R.M., Plagemann, W.L. 1985. A novel concept on the structure of cured urea-formaldehyde resin. The Journal of Adhesion 17: 275 295 .

Racich, J.L., Koutsky, J.A. 1976. Nodular structure in epoxy resins. Journal of Applied Polymer Science 20: $2111 \sim 2129$.

Ringena, O., Janzon, R., Pfizenmayer, G., Schulte, M., Lehnen, R. 2006. Estimating the hydrolytic durability of cured wood adhesives by measuring formaldehyde liberation and structural stability. HolzalsRoh- und Werkstoff 64: 321 326 .

Roffael, E., Hüster, H.-G. 2012. Complex chemical interactions on thermo hydrolytic degradation of urea formaldehyde resins (UF-resins) in re- cycling UF-bonded boards. European Journal of Wood and Wood Products 70: 401 405 .

Singh, A.P., Nuryawan, A., Park, B.D. 2013. A novel sample preparation method that enables ultrathin sectioning of urea-formaldehyde resin for imaging by transmission electron microscopy. Microscopy Research 1: $1 \sim 6$.

Singh, A.P., Causin, V., Nuryawan, A., Park, B.D. 2014. Morphological, chemical and crystalline features of urea-formaldehyde resin cured in contact with wood. European Polymer Journal 56: $185 \sim 193$.

Spurr, R.A., Erath, E.H., Myers, H., Pease, D.C. 1957. Curing process in phenolic resin electron-microscopic analysis. Industrial \& Engineering Chemistry 49(11): 1839 1842 .

Stuligross, J., Koutsky, J.A. 1985. A morphological study of urea-formaldehyde resins. Journal of Adhesion 18: $281 \sim 299$.

Tohmura, S., Hse, C.Y., Higuchi, M. 2000. Formaldehyde emission and high-temperature stability of cured urea-formaldehyde resins. Journal of Wood Science 46: 303 309. 